\title{
Enhanced liquid retention capacity within plastic food packaging through modified capillary recesses
}

\author{
Alaa Alaizoki ${ }^{\text {a, }}$, Christopher Phillips ${ }^{\mathrm{a}}$, Craig Hardwick ${ }^{\mathrm{b}}$, David Parker ${ }^{\mathrm{b}}$, Davide Deganello ${ }^{\mathrm{a},{ }^{* *}}$ \\ ${ }^{\text {a } W e l s h ~ C e n t r e ~ f o r ~ P r i n t i n g ~ a n d ~ C o a t i n g, ~ F a c u l t y ~ o f ~ S c i e n c e ~ a n d ~ E n g i n e e r i n g, ~ S w a n s e a ~ U n i v e r s i t y, ~ B a y ~ C a m p u s, ~ F a b i a n ~ W a y, ~ S w a n s e a, ~ S A 1 ~ 8 E N, ~ U n i t e d ~ K i n g d o m ~}$ \\ ${ }^{\mathrm{b}}$ Klockner Pentaplast, Wakefield Road, Featherstone, West Yorkshire, WF7 5DE, United Kingdom
}

\section{A R T I C L E I N F O}

\section{Keywords:}

Capillary valves

PET

Food packaging

Meat exudate

Liquid retention

\begin{abstract}
A B S T R A C T
A novel approach is proposed to isolate meat exudate in plastic packaging trays. This exudate is responsible for limiting meat shelf life, increasing meat loss and non-recycling plastic waste. This study explores the use of specially designed capillary recesses with integrated raised rims as a means of improving liquid retention capacity in thermoformed meat trays. The presence of raised recess rims is used to enhance the valving functionality of the recesses and restrict liquid drainage during and after recess inclination. This resulted in a considerable increase in liquid retention capabilities. For pork exudate, the retention capacity of recess samples (recess diameter: $9 \mathrm{~mm}$ ) significantly increased $(p<0.05)$ from $0.79 \mathrm{~g}$ for recesses with no rims to $2.12 \mathrm{~g}$ for rimintegrated recesses. The corresponding retention capacity of a recess array after introducing these rims was 2921 $\pm 63 \mathrm{~mL} / \mathrm{m}^{2}$. These recesses have comparable liquid scavenging performance to absorbent meat pads (3000 mL/ $\mathrm{m}^{2}$ ) yet are integrated within the tray material. This proves the practicality of using rim-integrated recesses in plastic meat packaging to retain exudate away and ensure fully recyclable plastic packaging. The manufacturing of these recesses is integrated into the thermoforming process for the tray body.
\end{abstract}

\section{Introduction}

Food supply chains and markets have rapidly been expanded and connected as a result of the globalisation and economic growth. Food packaging plays a crucial role in containing, preserving, and delivering food products within the global food chain (Lee, 2010; Schumann and Schmid, 2018). However, additional functionalities of the food packaging are increasingly sought to meet the needs of customers, dynamic food markets, and environmental considerations. The growth in world population and prosperity has increased the demand for safer and higher quality food products (Gaikwad et al., 2019; Schumann and Schmid, 2018). In 2050, the world's population will be over 9 billion with a rise in the food needs for nearly $70 \%$ (Cole et al., 2018). This may lead to a food insecurity with 1.3 billion tonnes/year of the global food supply wasted (FAO, 2011). Furthermore, the growing environmental impact of food packaging puts more pressure on the packaging industry to use recyclable packaging materials (Geueke et al., 2018; Lee, 2010). Plastics are the most used materials for packaging of food products in the supply chain, and this has recently been exacerbated by increased safety concerns and customer demand for pre-packaged food during the coronavirus pandemic (Kakadellis et al., 2021). Plastic materials are not typically biodegradable, and the majority of plastic food packaging is intended for a single use. This presents an environmental burden, with $<10 \%$ of plastic packaging waste being recycled, while most used plastic packaging is sent to landfill or ends up in oceans (Walker et al., 2021; Zhao et al., 2020).

The food packaging industry has been developing different functional packaging to address the major challenges of food packaging in managing food exudate, food shelf life, food waste, and packaging recyclability (Gaikwad et al., 2019; Gutierrez et al., 2017; Licciardello, 2017). Appropriate packaging of fresh meats is very crucial due to their perishability and susceptibility to the microbiological contamination (Schumann and Schmid, 2018). Meat, poultry, and fish naturally exude juice (exudate) during storage resulting in limited shelf life and large waste of the meat products (Gaikwad et al., 2019; Ren et al., 2018). This exudate primarily contains sarcoplasmic proteins generated from protein denaturation in muscles during the post-mortem period (Kim et al., 2013). The expressed exudate accounts for $1-3 \mathrm{wt} \%$ of a fresh meat product and can rise to $10 \mathrm{wt} \%$ for very exudative meat (Huff-Lonergan and Lonergan, 2005). Meat exudate is major challenge to plastic meat

\footnotetext{
* Corresponding author.

$* *$ Corresponding author.

E-mail addresses: 972353@swansea.ac.uk (A. Alaizoki), d.deganello@swansea.ac.uk (D. Deganello).
} 
packaging. It facilitates the deterioration of meat quality and safety due to high water activity, hence accelerated growth of spoilage and pathogenic microorganisms. The accumulated exudate may also leak from the packaging trays and is perceived as unsanitary by customers (Gaikwad et al., 2019; Gouvêa et al., 2016). Different packaging solutions have been developed to scavenge the free exudate in meat packaging. Plastic trays with absorbent pads or open-cell foam trays are widely used as soak-away packaging for the exudate released from fresh meat, poultry and fish (Maga et al., 2019; Realini and Marcos, 2014). Meat trays with small capillary features to trap the exudate under capillary forces are another popular packaging technique (Davidson et al., 2013). However, these packaging solutions are limited in their liquid scavenging capacity (Davidson et al., 2013; LaRue et al., 2011; Otoni et al., 2016), while soaked absorbent pads and foam trays with meat exudates also result in materials being more difficult to be recycled (Lanzani and Mauri, 1998; Licciardello, 2017). The landfill waste of the absorbent pads used in meat packaging has been estimated around 750 million pad/year just in Australia and New Zealand (Wheeler, 2019). Therefore, it is crucial to develop eco-friendly packaging solutions for the management of exudate within meat packaging.

Capillary phenomena (capillarity) offer the potential to produce plastic packaging trays with improved capabilities for isolating meat exudate. The capillarity depends on the capillary forces that define the liquid rise on a tilted solid surface or inside a thin tube in contact with wetting liquid reservoir (Si et al., 2018). The capillary forces govern liquid flow in the capillary systems where these forces are magnified in comparison with existing body forces (Patnaik et al., 2006; Ralston et al., 2008). Capillary stop valves are usually integrated into capillary systems to control the liquid flow, such as microfluidic devices. These valves are a sudden geometrical enlargement on a capillary channel where the liquid interface expands and adapts to the geometrical expansion. This induces a liquid pinning effect on the valve walls and generates a capillary pressure barrier to prevent the liquid flow (Cho et al., 2007; Glière and Delattre, 2006; Leu and Chang, 2004). The pinning effect of the capillary valves is magnified for larger enlargement angles, thus greater capillary forces and pressure barrier for improving liquid trapping and retention (Agonafer et al., 2015; Zimmermann et al., 2008). The capillary valve functionality has widely been studied for controlling the liquid flow in open capillary systems (Chen et al., 2008; Leu and Chang, 2004; Zimmermann et al., 2008), and liquid drainage in closed capillary systems, such as inclined tube with one closed end and container with small open orifice. Liquid drainage in an inclined tube with large opening is initiated by air finger evolving into the liquid meniscus (Kumar et al., 2018). This drainage mechanism is attributed to Taylor fingering phenomenon (Davies and Taylor, 1950).

In this context, liquid trapping in capillary tubes can be increased for improved pinning effect and stability of the liquid menisci, assuming the tube openings act as capillary valves. The increase in the expansion angle of capillary valves is critical for enhancing their liquid pinning effect and pressure barrier (Extrand, 2017; Wang et al., 2013). This technique can be exploited to design capillary liquid-holding recesses with enhanced pinning effects. Thus, larger capillary recesses with improved liquid retention capacity can be integrated into meat plastic tray to develop a packaging solution for isolation of meat exudate.

This work details an investigation into the use of capillary recesses, integrated with raised peripheral rims, as a means of improving liquid retention in plastic trays. The recess rims are proposed to improve the liquid pinning effects, hence liquid retention capacity of the recesses. Therefore, polyethylene terephthalate (PET) sheets were thermoformed to produce substrates with arrays of capillary recesses. PET was used in this study as it is the most common plastic material used in the manufacture of food packaging, particularly plastic meat trays (Maga et al., 2019; Nisticò, 2020).

\section{Materials and methods}

\subsection{Materials}

Polyethylene terephthalate (PET) sheets (nominal thickness: 0.5 $\mathrm{mm}$ ) were supplied and thermoformed in Klockner Pentaplast company (UK) to produce substrates with capillary recesses for liquid retention tests. The recesses were dipped and rinsed with Isopropyl alcohol (IPA) (Propan-2-ol $\geq 99.5 \%$, Fisher Scientific, UK) to remove any organic contaminants prior to testing. Aqueous test liquids were prepared to mimic meat exudate using sodium carboxymethyl cellulose (CMC) (Molecular weight: 90,000 g/mol, Sigma Aldrich, UK) as a rheology modifier and Triton X-100 surfactant (Sigma Aldrich, UK) to prepare test liquids of different surface tensions $(\gamma)$. Exudate collected from plastic packaging of fresh meat pork (mainstream retailer, UK) was used in retention tests. 4-Hydroxy-4-methyl-2-pentanone (Density: $0.931 \mathrm{~g} / \mathrm{mL}$, surface tension: $32.37 \mathrm{mN} / \mathrm{m}$, Sigma Aldrich, UK) was stained with methylene blue dye (M9140-25G, Sigma Aldrich, UK) to measure cavity volume of the thermoformed recesses. Trace amounts of red azorubine colorant- E122 (FastColours LLP, UK) was added to stain the test liquids in retention tests.

\subsection{Prototype and thermoforming of substrates with capillary recesses}

3D prototype models of two flat substrates with arrays of circleshaped recesses were designed to act as liquid-holding wells by SolidWorks designer software (Edition SP 4.0-2016) (Leite et al., 2018). One design included recesses with no rim and the other had recesses with peripheral rims raised above the substrate surface (rim height: $2 \mathrm{~mm}$, rim width: $0.5 \mathrm{~mm}$ ). The substrates were both configured into arrays of 8 -recess each with the same recess size and equally spaced. The recesses had circular-peripheral shapes with cavity depths of $5 \mathrm{~mm}$. The recess walls had a draft angle of $10^{\circ}$ and the recess opening diameters were 7 , $8,9,10,11,12 \mathrm{~mm}$. Other 3D models were designed for substrates and recesses with different combinations of rim height and width. These models were used to produce thermoformed PET parts as shown in Fig. 1. The mould manufacturing and thermoforming of PET sheets into substrates with recesses were conducted in Klockner Pentaplast Company, UK.

\subsection{Dimensions and volume measurement of thermoformed PET recesses}

The geometrical dimensions (opening diameter, cavity depth, draft angle, rim height, rim width) were determined for the PET recesses. Stitched 2D images of the recess cross-sections were acquired using Smartzoom 5 microscopy (Zeiss, UK). The resulting cross-section profiles were used to measure the dimensions of the recesses with nominal diameters of 7, 8, 9, 10, 11, $12 \mathrm{~mm}$ (Carey et al., 2018; Erdogan and Eksi, 2014). The volume measurement of the recess cavities was based on the mass of a liquid filling the recess cavity. The recesses of the studied sizes were filled with 4-Hydroxy-4-methyl-2-pentanone coloured with methylene blue dye, and the corresponding liquid masses were then measured. This liquid had a specific density and low surface tension to provide a good liquid levelling with the recess openings. The recess volume was defined as the volume of the liquid occupying the recess cavity and determined by the measured liquid mass and density (Sahin and Sumnu, 2007).

\subsection{Wettability and surface energy of PET recesses}

The wettability of PET samples (recess and substrate surfaces) was characterised by the sessile drop technique. Small drops $(3 \mu \mathrm{L})$ of deionised (DI) water were placed on clean flat PET surface and the measurement of their static contact angles were carried out in a goniometer (First Ten Angstroms FTA1000c analyser) (Vesel et al., 2008; Zhao and Jiang, 2018). The surface energy of the PET sample surfaces 


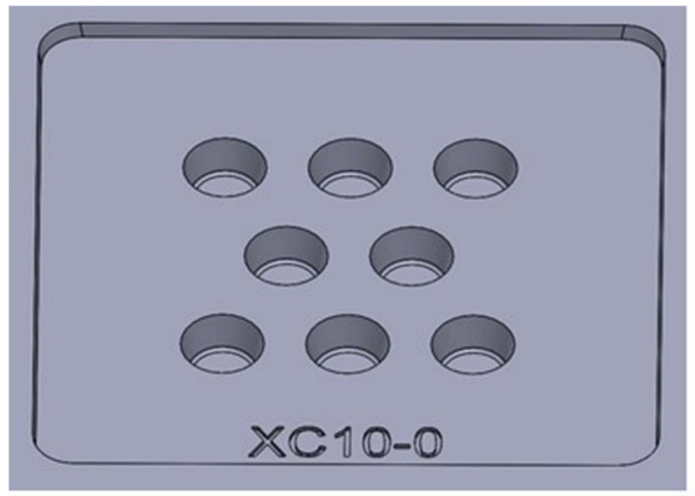

(a)

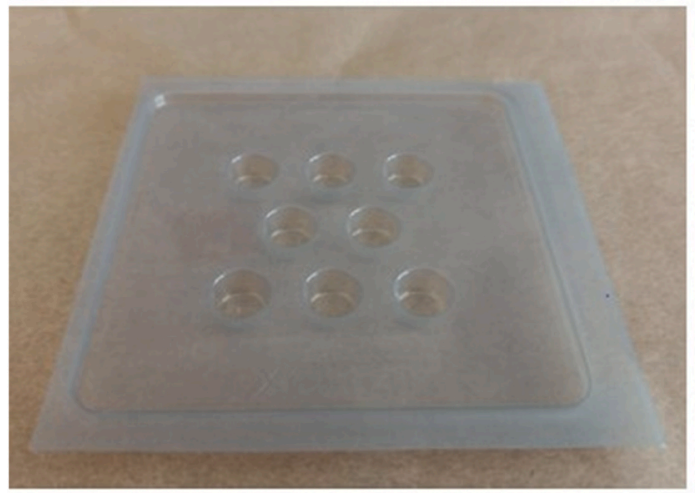

(c)

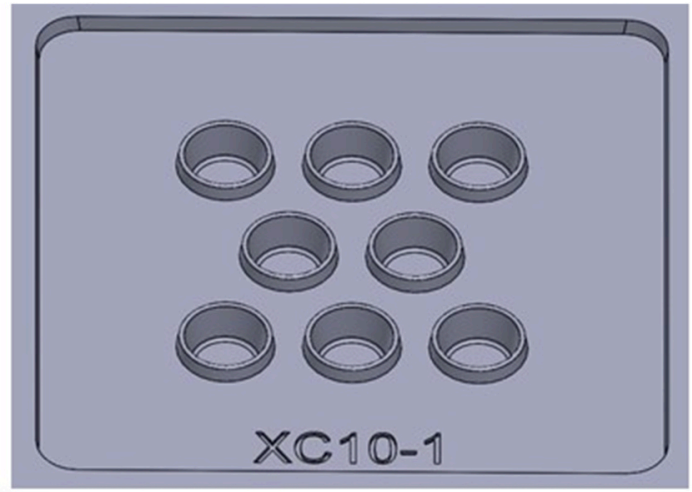

(b)

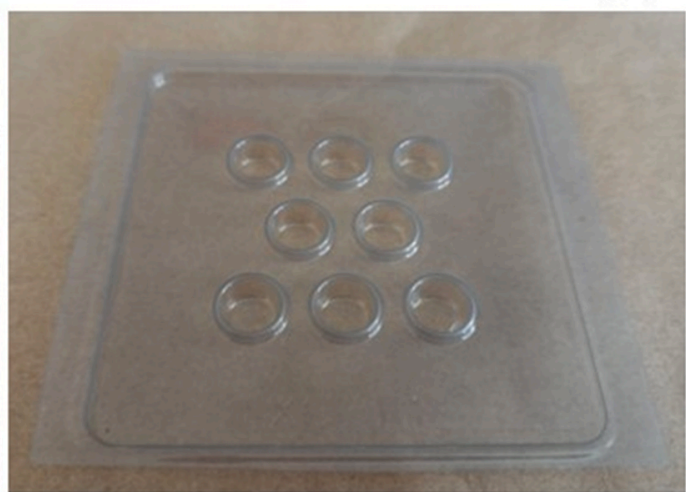

(d)

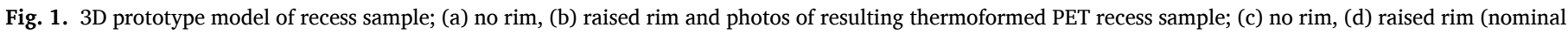
recess diameter: $10 \mathrm{~mm}$ ).

was measured using polar and non-polar liquids represented by DI water and diiodomethane (Sigma Aldrich, 158,429- 25 ML, UK) respectively. The surface energy values were determined by Owens-Wendt method as described in another work (Yang et al., 2009). The contact angle measurements were performed at temperature of $20 \pm 1{ }^{\circ} \mathrm{C}$ and relative humidity of $54 \pm 5 \%$.

\subsection{Preparation of test liquids}

Test liquids were prepared as meat exudate simulants from CMC $1 \mathrm{wt}$ $\%$ solutions with varying amounts of Triton X-100 surfactant. CMC is widely used as a food thickener and diluted CMC solutions exhibit Newtonian behaviour (Klimovič and Pekař, 2007; Miehle et al., 2021). The prepared liquids mimicked the rheological characteristics of meat exudate found in previous studies (Farouk et al., 2012; Hertog-Meischke et al., 1998; Ursu et al., 2016), and had different surface tension values $(\gamma: 72.6,52.3$ and $31.5 \mathrm{mN} / \mathrm{m}$ ) to cover a broad range of surface tensions that could be found in exudate. The surfactant addition to the test liquids had no effect on their dynamic viscosity of $5.60 \pm 1.34 \mathrm{mPa} s$ and density of $1.002 \pm 0.001 \mathrm{~g} / \mathrm{mL}$. A gravity pycnometer (volume: $10 \mathrm{~cm}^{3}$, Fisher Scientific Ltd) was used to determine the density of the test liquids (Guo et al., 2012). Flow behaviour of the test liquids was characterised by defining their shear viscosity on a rotary rheometer (Gemini HR nano Rheometer) using parallel plates (diameter: $60 \mathrm{~mm}$, gap: $400 \mu \mathrm{m}$ ) (Ursu et al., 2016). A goniometer (First Ten Angstroms FTA1000c) was used to measure the surface tension of the test liquids according to the shape profile of their pendant drops (Berry et al., 2015). The measurements of the physical and rheological properties of the CMC $1 \mathrm{wt} \%$ were carried out at temperature of $20 \pm 1{ }^{\circ} \mathrm{C}$. The test liquids were stained with food red colorant (azorubine- E122, FastColours LLP) to improve their visualisation in the retention tests (Extrand, 2017).

\subsection{Retention test of PET recesses}

Retention tests were conducted to assess liquid holding capacity of the PET recesses for combinations of varying recess sizes and rim presence. The recess samples (8-recess arrays) were placed horizontally, filled with test liquids and then tilted upside down on a rotating board over a period of $5 \mathrm{~s}$. The weight of test liquid in the recess samples was determined before and after tilting. The liquid retention capacity $(\mathrm{g})$ was defined by the weight of liquid retained in recesses after tilting (Extrand, 2018). The retention tests were also performed for recess samples with combinations of varying rim heights and widths. For practicality of using the recesses in food packaging, the retention capacity of recesses with best liquid retention performance was calculated in $\mathrm{mL} / \mathrm{m}^{2}$. This corresponded to the liquid volume retained in recesses with hexagonal packing (recess spacing: $1 \mathrm{~mm}$ ) on $1 \mathrm{~m}^{2}$ of PET substrate (Wardhani et al., 2014).

\subsection{Statistical analysis}

Liquid retention capacities of the PET recesses were measured in triplicate and the obtained data were evaluated as mean \pm standard deviation. One-way ANOVA method through SPSS software (IBM Corporation, SPSS Statistics- Version: 28, USA) was used to analyse the data to determine the statistical significance of differences between the means at probability value $p<0.05$ (Saedi et al., 2021). 


\section{Results}

\subsection{Analysis of geometrical dimensions, volume and surface properties of} PET recesses

The thermoformed PET recess samples revealed a comparable replication of their 3D prototype models as shown in Fig. 1. This was also demonstrated in the cross-section profiles and geometrical dimensions of the PET recesses in comparison with their prototype models. The shape profile and key dimensional measurements of PET recess and its prototype model (nominal diameter: $10 \mathrm{~mm}$ ) are illustrated in Fig. 2. Table 1 shows the recess volumes for the various nominal diameters of recess openings. Capacities increased with nominal diameter and there was close agreement between capacities with rims and no rims (error $<0.007 \mathrm{~mL}$ ). Table S1 and S2 in supplementary data show the geometrical dimensions of the PET recesses with nominal opening diameters of $7,8,9,10,11,12 \mathrm{~mm}$. All recesses showed wall thinning and uneven thickness distribution in the recess walls. The recess openings formed round edges, therefore, the opening diameter was defined as the distance between the bottoms of opposing round edges on the recess crosssection profiles. The measured dimensions of PET recesses were consistent with their prototype models as shown in Table S1 and S2 in supplementary data. The opening diameters of the recesses with raised rim and with no rim had errors $<0.211 \mathrm{~mm}$ and $<0.156 \mathrm{~mm}$ respectively in comparison with their nominal diameters. The cavity depths of the corresponding PET recesses had also small errors $<0.178 \mathrm{~mm}$ and $<0.137 \mathrm{~mm}$ respectively. Although the geometrical dimensions of PET recess rims slightly deviated from their nominal dimensions (height and width), these rims were dimensionally consistent for the studied recess sizes. For PET recesses with different rim heights and widths, the recess geometrical dimensions were also consistent as presented in Table S3 and S4 in supplementary data.

The wetting properties of the PET recesses were characterised by the measured water contact angles on the PET sample surface. The cleaned PET surface showed water contact angle of $75.23 \pm 0.74^{\circ}$ with consistent measured values on the recess and substrate surfaces. This lack of hydrophilicity corresponded to the measured low surface energy of $48.14 \mathrm{~mJ} / \mathrm{m}^{2}$.
Table 1

Cavity volumes of thermoformed PET recesses.

\begin{tabular}{lll}
\hline Nominal diameter $(\mathrm{mm})$ & \multicolumn{2}{l}{ Recess volume $(\mathrm{mL})$} \\
\cline { 2 - 3 } & Raised rim & No rim \\
\hline 7 & $0.148 \pm 0.003$ & $0.151 \pm 0.003$ \\
8 & $0.202 \pm 0.002$ & $0.208 \pm 0.002$ \\
9 & $0.262 \pm 0.003$ & $0.266 \pm 0.002$ \\
10 & $0.329 \pm 0.009$ & $0.331 \pm 0.001$ \\
11 & $0.409 \pm 0.003$ & $0.412 \pm 0.002$ \\
12 & $0.478 \pm 0.011$ & $0.485 \pm 0.004$ \\
\hline
\end{tabular}

Mean values \pm sample standard deviation $(n=3)$.

\subsection{Analysis of liquid retention of PET recesses}

The liquid retention capacity of thermoformed PET recesses was evaluated with test liquids of different surface tensions (solutions A, B, C) and real pork exudate (solution D) as shown in Table 2.

\subsubsection{Recesses with rims $v s$ recesses with no rims}

The effect of incorporating rims on liquid retention capability of PET recesses was evaluated by comparing recess samples (8-recess arrays) with raised rims (rim height: $2 \mathrm{~mm}$ and rim width: $0.5 \mathrm{~mm}$ ) against their corresponding samples with no rims. The retention capacity was estimated in grams for a combination of various recess sizes and liquid surface tensions under normal gravity. Fig. 3 illustrates the relative retention capacities with nominal recess diameter of $10 \mathrm{~mm}$ with solution A (without surfactant). The test liquid in the tilted recess sample with no rim notably drained, while the liquid remained trapped in the

Table 2

Composition and surface tension of test liquids.

\begin{tabular}{lll}
\hline Test liquid & Composition & Surface tension $(\mathrm{mN} / \mathrm{m})$ \\
\hline Solution A & CMC 1 wt $\%$ & $72.6 \pm 0.3$ \\
Solution B & CMC 1 wt $\%$ + surfactant $0.0025 \mathrm{wt} \%$ & $52.3 \pm 0.5$ \\
Solution C & CMC 1 wt $\%$ + surfactant $0.1 \mathrm{wt} \%$ & $31.5 \pm 0.1$ \\
Solution D & Real pork exudate & $60.0 \pm 1.2$ \\
\hline
\end{tabular}

Mean values \pm sample standard deviation $(\mathrm{n}=3)$.

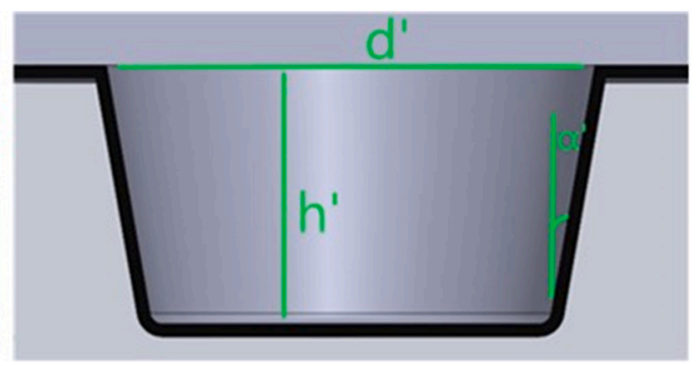

(a)

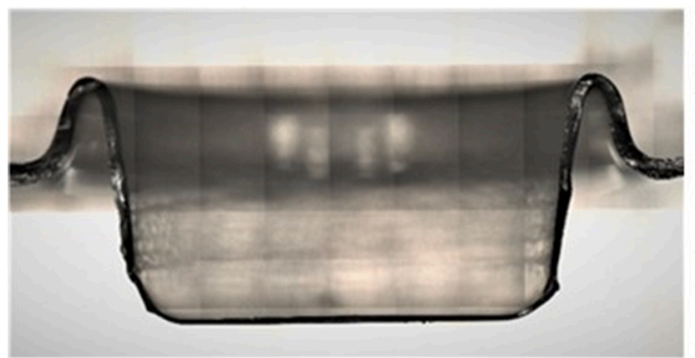

(c) (b)

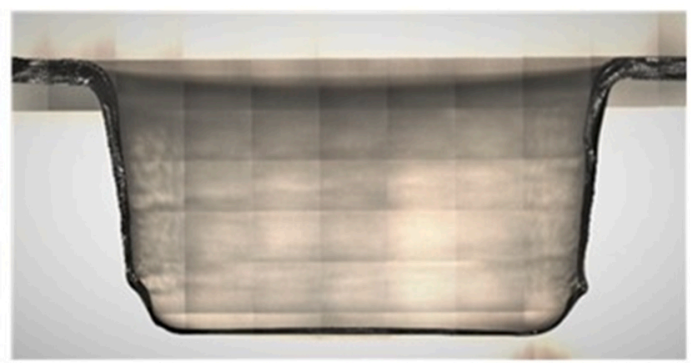

(d)

Fig. 2. Cross-section profiles of recess model; (a) raised rim, (b) no rim and thermoformed PET recess; (c) raised rim, (d) no rim (nominal diameter: 10 mm). 


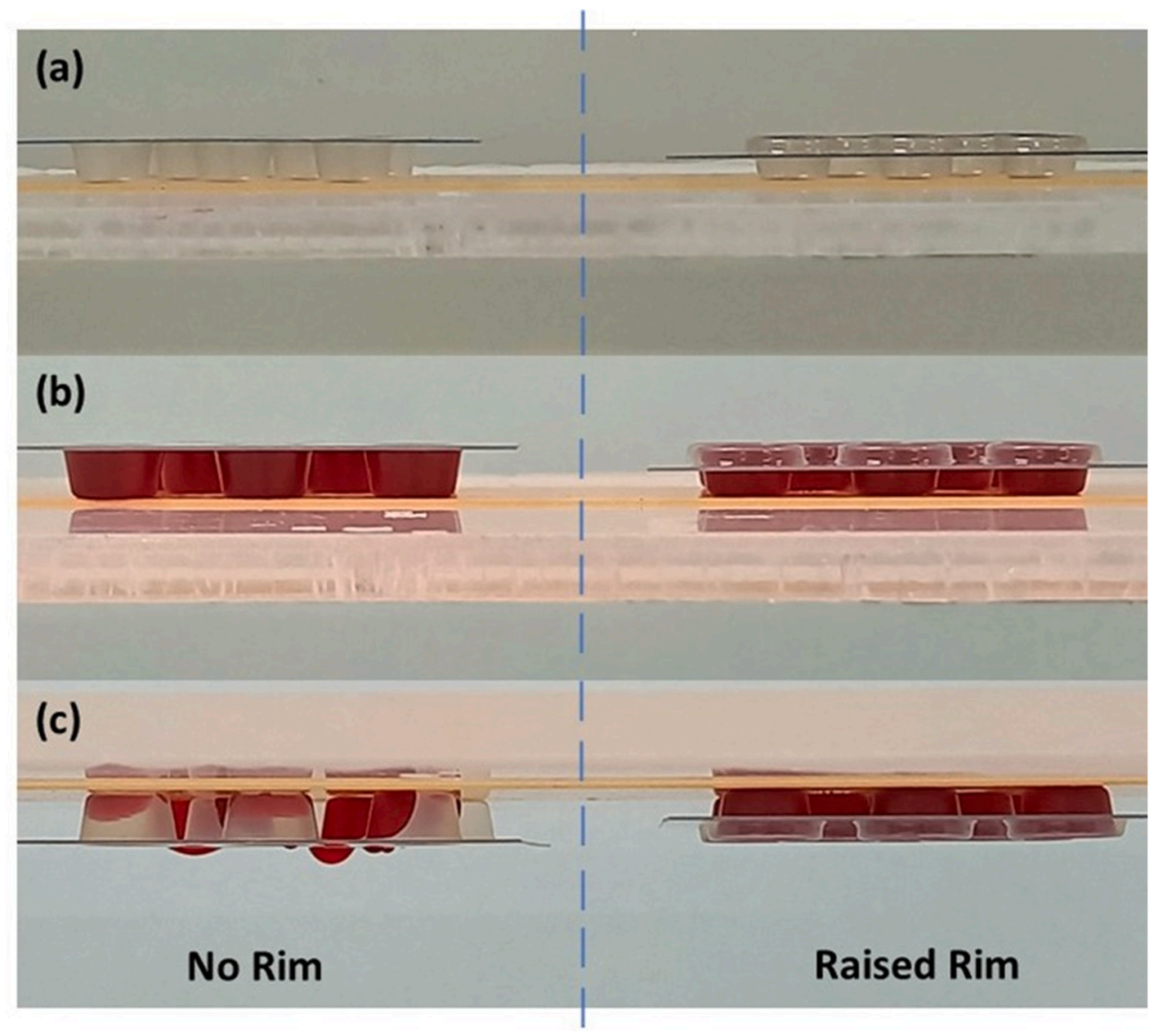

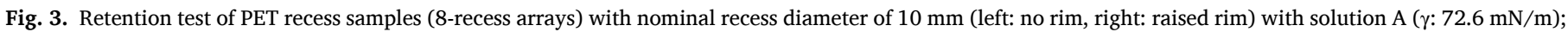
(a) empty recesses, (b) before tilting, (c) after tilting.

tilted sample with the raised rim. Comparisons of liquid retention capacity of recess samples (nominal recess diameter: 7, 8, 9, 10, 11, 12 $\mathrm{mm}$ ) with solutions A, B, C, and D are shown in Fig. 4. Retention capacity of recess samples was affected by nominal diameter, the presence of rims and the surface tension of the test liquid. The presence of integrated recess rims considerably improved the liquid retention capacity of the PET recesses with all test liquids including the real pork exudate. This was most strongly observed for samples (recess diameter of $10 \mathrm{~mm}$ ) with solution A (without surfactant), and samples (recess diameter of 9 $\mathrm{mm}$ ) with solutions B and D (intermediate surface tension liquid and pork exudate respectively) $(p<0.05)$ as shown in Fig. $4 \mathrm{a}, \mathrm{b}$, and $\mathrm{d}$. This corresponded to retention capacities of $2.53 \mathrm{~g}, 2.02 \mathrm{~g}$ and $2.12 \mathrm{~g}$ for rimintegrated recess samples respectively. On the other hand, the retention capacities of the corresponding samples with no rims were only $0.79 \mathrm{~g}$, $0.53 \mathrm{~g}$ and $0.79 \mathrm{~g}$ respectively. The beneficial effect of recess rim was reduced with the increase in recess sizes as the liquid in the tilted recesses drained more readily. This occurred for the samples of recess diameters $>10 \mathrm{~mm}$ with solution A and $>9 \mathrm{~mm}$ with solutions B and D. For samples with small recess diameters, such as $7 \mathrm{~mm}$ and $8 \mathrm{~mm}$, the tilted recesses with solutions A and B maintained full regardless the presence of raised recess rims.

The liquid surface tension had a significant effect on the liquid retention of the recess samples as their retention capacity increased for higher surface tension liquids. The increase in liquid surface tension also magnified the effect of recess rim on enhancing the retention capacity. However, at very low surface tensions, with solution C, the recess samples lost their retention capacity. This very low surface tension of the test liquid facilitated liquid drainage for the recesses of all sizes with only slight improvement in the retention capacity for samples with raised rims as shown in Fig. 4c. The liquid retention was also evaluated in terms of the liquid volume $(\mathrm{mL})$ that can be trapped per square metre of PET substrate with recesses. Therefore, the retention capacity (mL/ $\mathrm{m}^{2}$ ) was estimated for hexagon-packed recesses (recess diameter: $9 \mathrm{~mm}$ ) with even spacing distance of $1 \mathrm{~mm}$ (Wardhani et al., 2014). The retention capacity of the rim-integrated recesses with solutions B and D (intermediate surface tension liquid and pork exudate respectively) was $2898 \pm 66$ and $2921 \pm 63 \mathrm{~mL} / \mathrm{m}^{2}$ respectively, while the corresponding recesses with no rims had retention capacities of $763 \pm 288$ and $1059 \pm$ $126 \mathrm{~mL} / \mathrm{m}^{2}$ respectively. This can validate the practicality of introducing recesses with raised rims to the plastic meat packaging considering the limited draw ratios that can be achieved for plastic packaging trays.

\subsubsection{Rim height and width}

The effects of the geometrical dimensions of the recess rim on liquid retention capacity were studied for rim-integrated recess samples of mid-range surface tension (solution B). The liquid retention capacities of recess samples (nominal recess diameter: $9 \mathrm{~mm}$ ) with different rim heights and widths are shown in Fig. $5 \mathrm{a}$ and $\mathrm{b}$ respectively. For recess samples with nominal rim width of $0.5 \mathrm{~mm}$, rim heights of $0.2 \mathrm{~mm}$ were sufficient to give the full retention capacity, with no benefit in increasing the rim height further. The recess samples showed partial liquid drainage with a decrease in the retention capacity from $2.02 \mathrm{~g}$ to $1.18 \mathrm{~g}$ for rim height of $0.1 \mathrm{~mm}$. On the other hand, recess samples with nominal rim height of $2 \mathrm{~mm}$ and varied rim widths $(0.2-5 \mathrm{~mm})$ in Fig. $5 \mathrm{~b}$ showed that the recess samples with rim widths of $0.2-0.5 \mathrm{~mm}$ maintained their full liquid retention capacity, but that further increases in rim width reduced the capacity so that the retention capacity was partially lost from $2.02 \mathrm{~g}$ to $1.23 \mathrm{~g}$ for rim width of $1 \mathrm{~mm}$. The retention capacity then further decreased for wider rims until the recess samples 


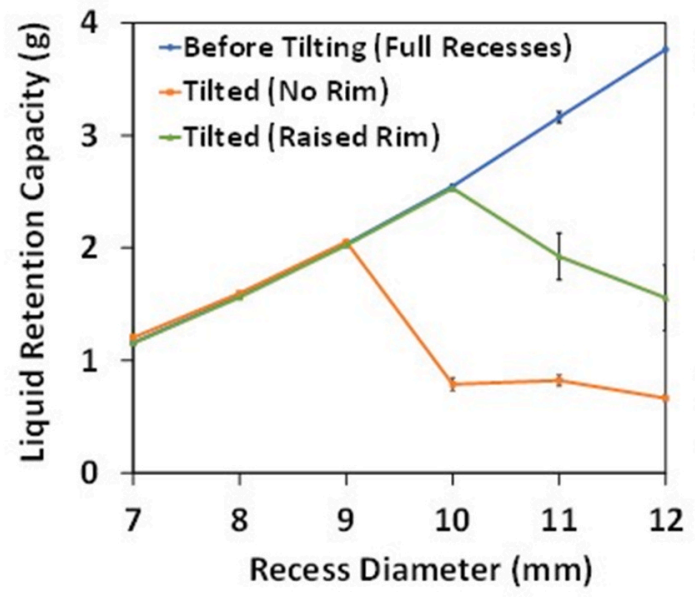

(a)

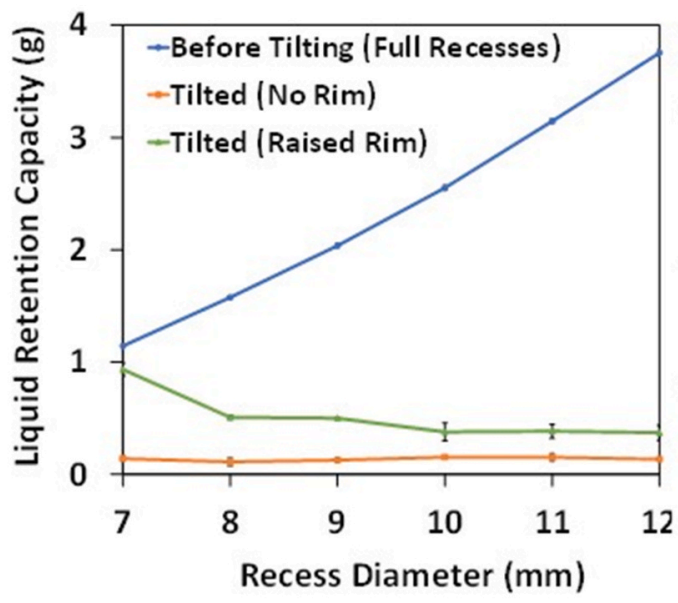

(c)

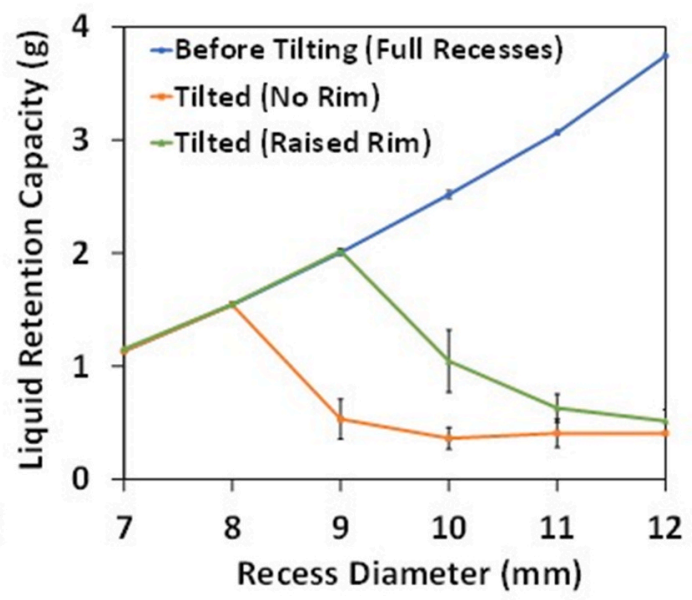

(b)

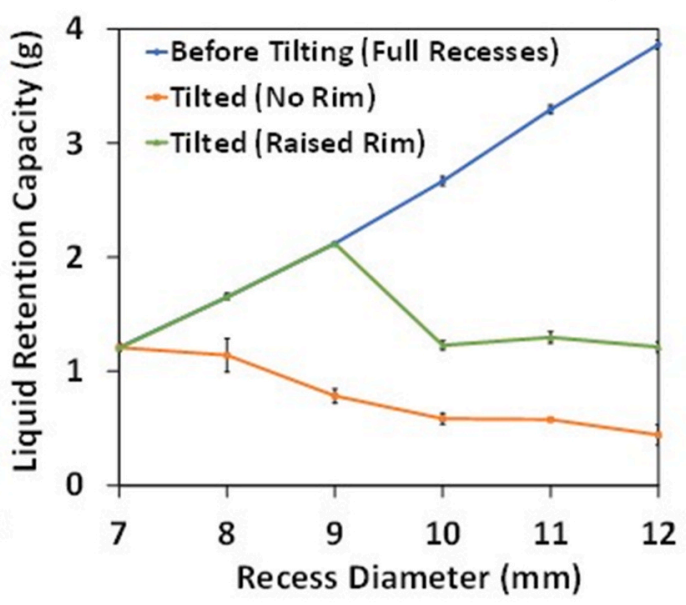

(d)

Fig. 4. Liquid retention capacity of tilted PET recess samples (8-recess arrays) with raised rim and with no rim; (a) solution A ( $\gamma: 72.6 \mathrm{mN} / \mathrm{m})$, (b) solution B ( $\gamma: 52.3$ $\mathrm{mN} / \mathrm{m})$, (c) solution C ( $\gamma: 31.5 \mathrm{mN} / \mathrm{m})$, (d) solution $\mathrm{D}(\gamma: 60.0 \mathrm{mN} / \mathrm{m})$.

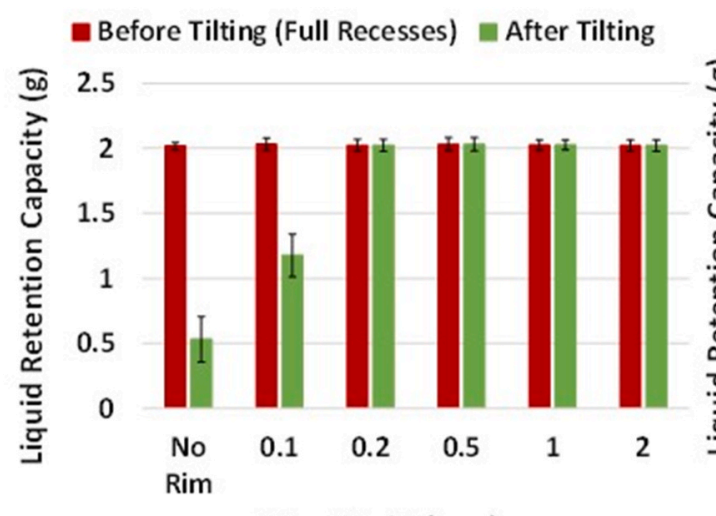

Rim Height $(\mathrm{mm})$

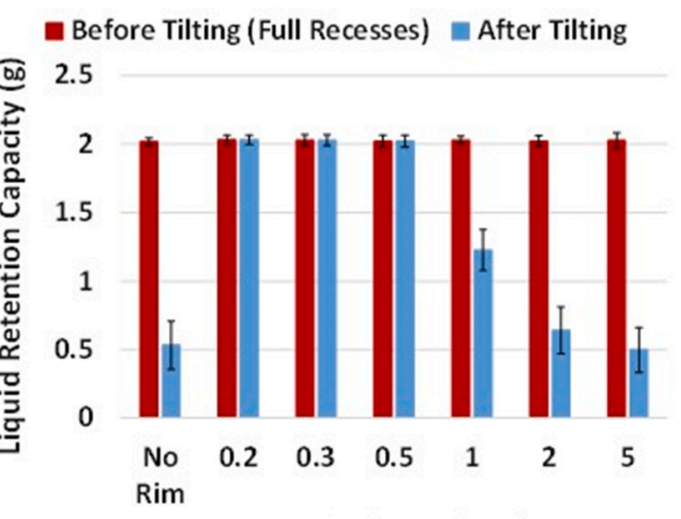

Rim Thickness (mm)

(a)

Fig. 5. Liquid retention capacity of tilted PET recess samples (8-recess arrays, nominal recess diameter: $9 \mathrm{~mm}$ ) with solution B ( $\gamma: 52.3 \mathrm{mN} / \mathrm{m})$; (a) different rim heights, (b) different rim widths. 
were comparable with samples with no rim.

\section{Discussion}

\subsection{Characteristics of recess geometry and dimensions}

The thermoforming process of the PET substrates allowed consistent replication of the recesses with their 3D prototype models. The thermoforming technology is widely used in the food packaging industry and performs effectively for both simple and relatively complex-shaped plastic packaging products (McCool and Martin, 2011). The variations in wall thickness distribution of the PET recesses occurred as the heated polymeric sheet deforms on the mould during the thermoforming process. This is usually observed in thermoformed plastic products, such as food trays (Buntinx et al., 2014). The relaxation and stress residuals releasing experienced by thermoformed plastic products might also play role in the small scale variation of the recess dimensions (Ashter, 2014; Morye, 2005; Throne, 2017). Therefore, the current thermoforming technology, used for the manufacture of conventional plastic food trays, is fit for the intended purpose giving sufficient accuracy to produce a range of recess sizes at scale.

\subsection{Liquid retention capacity of PET recesses}

The low polarity and surface energy of PET surface resulted in low surface wettability of the recess surfaces (Awaja et al., 2009; Yang et al., 2009). The raised rims introduced to the PET recesses with this consistent low surface wettability increased their liquid retention capacity. This enables design and thermoforming of plastic meat trays with capillary rim-integrated recesses for improved liquid self-isolation. These trays can trap the exudate released from packaged meat products during their shelf lifetime. The mechanism of the capillary liquid retention fundamentally depends on the effects of liquid pinning and dominant pressures on the liquid menisci. This was described in studies conducted by Extrand $(2018,2017)$ on the capillary liquid trapping and draining in tubes and enclosures with small orifices. A liquid in inclined tube or capillarity forms air-liquid interface on its open bottom end that undergoes capillary, hydrostatic and atmospheric pressures (Extrand, 2017). While the atmospheric pressure upwardly pushes the liquid into the capillarity cavity against the encountering hydrostatic pressure, it introduces air fingers into the liquid bulk for unstable liquid menisci as illustrated within capillary recess in Fig. 6a. This phenomenon is called Taylor finger, which can propagate into the liquid leading to liquid draining out from the capillarity opening (Davies and Taylor, 1950; Extrand, 2017; Kumar et al., 2018). However, geometrical valves usually introduced to capillary systems improve the liquid pinning on their expanded walls leading to increases in the pressure barrier. The PET recesses have a capillarity structure with recess openings acting as geometrical valves. These openings allow the liquid to be pinned on their edges, and hence the capillary pressure generates a local pressure barrier to prevent liquid drainage (Wang et al., 2013). This results in more stable menisci and improved resistance to air finger formation that causes the liquid drainage (Kumar et al., 2018). The capillary pressure and stability of the liquid menisci significantly improved with the decrease in recess sizes. Therefore, liquid menisci in the tilted small recesses were stable with a sufficient pressure barrier to restrict Taylor finger development. This allowed atmospheric pressure to prevent the liquid drainage from the recess cavities as described by Extrand (2017). This was manifested as full liquid retention in inclined recesses with diameter of $7 \mathrm{~mm}$ regardless the presence of raised rim. However, the liquid curvature and capillary pressure decreased for larger recesses (Extrand, 2017). This could reduce the menisci stability and undermine the liquid pinning on the recess openings. Thus, the air finger was initiated since the pressure barrier was not sufficient to resist the growing local hydrostatic pressure during the recess inclination (Extrand, 2017, 2018; Kumar et al., 2018). This resulted in liquid drainage of the recess cavities as manifested in the reduced liquid retention of larger sized recesses, notably for recesses with no rim.

The presence of thin recess rims above the substrate surface enhanced the valving functionality of the recess openings. The raised rim introduced a larger expansion angle to the recess opening, which improved their liquid pinning effect and the capillary pressure barrier (Cho et al., 2007; Thio et al., 2013), with the proposed action illustrated in Fig. 6b. The increased expansion angle of the recess openings leads to an increase in maximal contact angle that liquid menisci form on the rim edges of the recesses. The resulting liquid menisci were more stable with stronger pinning on the recess rims as explained by Wang et al. (2013). This improved the resistance of the liquid menisci to air finger development and liquid drainage, especially for larger recesses in comparison with their corresponding recesses with no rims. Therefore, the introduced recess rims led to considerable increases in liquid retention capacity of the capillary recesses. The liquid retention of the rim-integrated recesses was also enhanced with real pork exudate, demonstrating the real-world application of this technology. This reveals that the improved valving functionality by recess rims was insensitive to the presence of proteins in the liquid. However, the liquid retention capacity decreased for lower liquid surface tensions as the liquid menisci exhibited less stability and pressure barrier. The reduction in liquid surface tension reduced the resistance to the liquid drainage by facilitating the propagation of air finger as explained by Kumar et al. (2018). The PET recesses with the very low surface tension liquid $(\gamma: 31.5 \mathrm{mN} / \mathrm{m}$ ) lacked retention capabilities. This could be attributed to the lost pinning effect as the PET substrate had surface energy $\left(48.14 \mathrm{~mJ} / \mathrm{m}^{2}\right)$, higher than the surface tension of the test liquid. Therefore, the liquid fully wetted the recess edges resulting in liquid drainage out of the recess cavities. Although the raised recess rim improved the liquid pinning effect, it only led to slight increases in the retention capacity with the very low surface tension liquid for the studied recess sizes. However, meat exudates are unlikely to have such low surface tension (Ursu et al., 2016).

The geometrical dimensions of the recess rims determined the effectiveness of their valving functionality in enhancing the liquid retention capacity. A minimum rim height $(0.2 \mathrm{~mm})$ was required for the full liquid pinning effect, while the recesses with rims of lower height

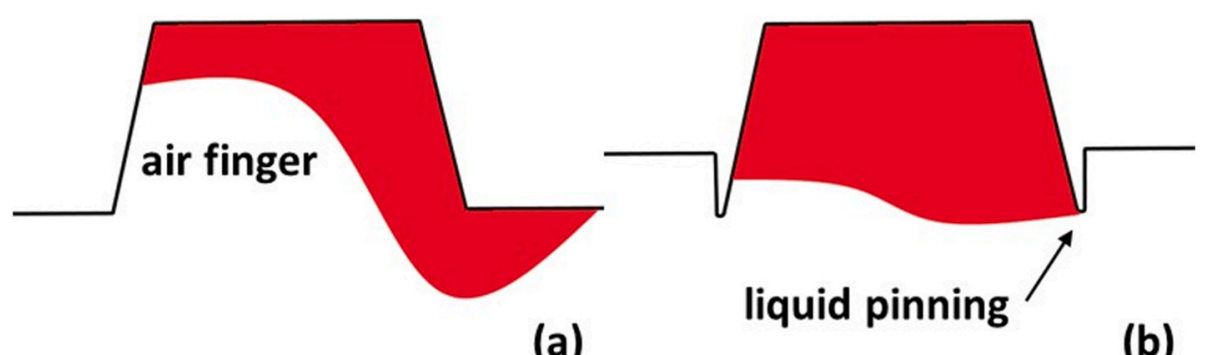

(a)

(b)

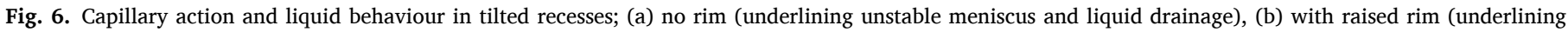
stable meniscus and liquid retention). 
$(0.1 \mathrm{~mm})$ showed decreased capacity for enhanced liquid retention. The rim width also governed the improvement in liquid retention capacity by influencing the liquid pinning and pressure barrier. Larger rim widths reduced the sharpness of the raised rim, diminishing the effectiveness of the increased expansion angle. This was comparable with the study findings about liquid trapping on capillarity tips as reported by Agonafer et al. (2015).

This study demonstrates that recesses integrated with thin rims can be an effective technology to isolate the exudate in plastic meat packaging. For pork exudate, rim-integrated PET recesses with opening diameter of $9 \mathrm{~mm}$ had retention capacity of $2921 \pm 63 \mathrm{~mL} / \mathrm{m}^{2}$ reflecting an increase of 2.76 times when compared with recesses with no rims. This improved retention capacity is comparable to the absorbent pads used in plastic meat trays, which typically have a liquid absorption capacity of $\sim 3000 \mathrm{~mL} / \mathrm{m}^{2}\left(2949 \mathrm{~mL} / \mathrm{m}^{2}\right.$ based on experimental testing with a simulant liquid). The recesses with raised rims have a permanent effect with low manufacturing cost as the recess production takes place during the normal forming stage. Further, meat exudate trapped in the PET recesses with raised rims can be readily removed by washing the recesses with water to be ready for the recycling process. This allows the manufacture of fully recyclable meat trays, and replaces the use of the non-recyclable absorbent pads that restrict the recycling process of plastic trays and have additional material cost and associated labour (LaRue et al., 2011). It can also reduce the footprint of the overall plastic packaging waste.

\section{Conclusions}

The integration of raised thin rims on to PET capillary recesses with extended sizes was an effective technology to substantially enhance their capacity to retain liquids. The PET recesses with raised rims exhibited increases in liquid retention capacity (by 2.76 times for recess diameter of $9 \mathrm{~mm}, \gamma: 60.0 \mathrm{mN} / \mathrm{m}$ ) in comparison to the recesses with no rims. The introduced thin rims improved the valving functionality of the recess openings throughout increasing their expansion angles. The liquid menisci on the recess openings were more stable and resistant to liquid drainage. This approach is a promising solution for exudate scavenging in plastic meat packaging. The manufacturing of plastic meat trays with arrays of rim-integrated recesses can be easily scaled up and incorporated in to the existing tray forming process. These plastic trays can be made from a single polymeric material, such as polyethylene terephthalate, polypropylene and polyethylene to produce fully recyclable trays, while the design of the recesses allows used trays to be rinsed and cleaned to directly enter closed loop recycling. Therefore, many plastic trays will be recycled to reduce the burden of plastic packaging waste on the environment. The plastic trays that are incorporated with recesses also avoid the need for conventional absorbent pads, which are non-recyclable materials and commonly sent as waste to the landfill. While the new packaging solution was developed for scavenging the exudate in meat packaging, it can be applied to packaging of other liquid-exuding food products.

\section{Credit author statement}

Alaa Alaizoki: Investigation, Conceptualisation, Methodology, Writing - original draft, Visualisation. Christopher Phillips: Supervision, Writing - review \& editing, Validation. Craig Hardwick: Resources, Supervision, Project administration. David Parker: Supervision. Davide Deganello: Conceptualisation, Supervision, Methodology, Writing - review \& editing, Validation, Project administration.

\section{Declaration of competing interest}

The authors declare the following financial interests/personal relationships which may be considered as potential competing interests:
Authors declare that a patent (Application number: GB2014346.7) has applied in relation to this work and commercialised by Klockner Pentaplast.

\section{Acknowledgements}

This work was financially supported by Materials and Manufacturing Academy (M2A) through funding from the European Social Fund via the Welsh Government (c80816), the Engineering and Physical Sciences Research Council (UK) (Grant Ref: EP/L015099/1) and Klockner Pentaplast Group. Furthermore, we would like to acknowledge the assistance provided by Swansea University, Faculty of Science and Engineering, AIM Facility, which was funded in part by the EPSRC (EP/ M028267/1), the European Regional Development Fund through the Welsh Government (80708) and the Ser Solar project via Welsh Government.

\section{Appendix A. Supplementary data}

Supplementary data to this article can be found online at https://doi. org/10.1016/j.jfoodeng.2022.111010.

\section{References}

Agonafer, D.D., Lopez, K., Palko, J.W., Won, Y., Santiago, J.G., Goodson, K.E., 2015. Burst behavior at a capillary tip: effect of low and high surface tension. J. Colloid Interface Sci. 455, 1-5. https://doi.org/10.1016/j.jcis.2015.05.033.

Ashter, S.A., 2014. The thermoforming process. In: Thermoforming of Single and Multilayer Laminates, pp. 13-38. https://doi.org/10.1016/b978-1-4557-3172 5.00002-5.

Awaja, F., Gilbert, M., Kelly, G., Fox, B., Pigram, P.J., 2009. Adhesion of polymers. Prog. Polym. Sci. 34, 948-968. https://doi.org/10.1016/j.progpolymsci.2009.04.007.

Berry, J.D., Neeson, M.J., Dagastine, R.R., Chan, D.Y.C., Tabor, R.F., 2015. Measurement of surface and interfacial tension using pendant drop tensiometry. J. Colloid Interface Sci. 454, 226-237. https://doi.org/10.1016/j.jcis.2015.05.012.

Buntinx, M., Willems, G., Knockaert, G., Adons, D., Yperman, J., Carleer, R., Peeters, R., 2014. Evaluation of the thickness and oxygen transmission rate before and after thermoforming mono- and multi-layer sheets into trays with variable depth. Polymers 6, 3019-3043. https://doi.org/10.3390/polym6123019.

Carey, T., Jones, C., Le Moal, F., Deganello, D., Torrisi, F., 2018. Spray-coating thin films on three-dimensional surfaces for a semitransparent capacitive-touch device. ACS Appl. Mater. Interfaces 10, 19948-19956. https://doi.org/10.1021/ acsami.8b02784.

Chen, J.M., Huang, P.C., Lin, M.G., 2008. Analysis and experiment of capillary valves for microfluidics on a rotating disk. Microfluid. Nanofluidics 4, 427-437. https://doi. org/10.1007/s10404-007-0196-X.

Cho, H., Kim, H.Y., Kang, J.Y., Kim, T.S., 2007. How the capillary burst microvalve works. J. Colloid Interface Sci. 306, 379-385. https://doi.org/10.1016/j. jcis.2006.10.077.

Cole, M.B., Augustin, M.A., Robertson, M.J., Manners, J.M., 2018. The science of food security. npj Sci. Food 2, 14. https://doi.org/10.1038/s41538-018-0021-9.

Davidson, R.P., Becke, G.S., Minnett, J.C., 2013. Food Tray with Integrated LiquidRetention System. US8596490.

Davies, R.M., Taylor, G., 1950. The mechanics of large bubbles rising through extended liquids and through liquids in tubes. Proc. R. Soc. Lond. A. Math. Phys. Sci. 200, 375-390.

Erdogan, E.S., Eksi, O., 2014. Prediction of wall thickness distribution in simple thermoforming moulds. Stroj. Vestnik/Journal Mech. Eng. 60, 195-202. https://doi. org/10.5545/sv-jme.2013.1486.

Extrand, C.W., 2018. Drainage from a fluid-handling component because of inclination. Langmuir 34, 126-130. https://doi.org/10.1021/acs.langmuir.7b03791.

Extrand, C.W., 2017. Spontaneous draining of liquids from vertically oriented tubes. Langmuir 33, 12903-12907. https://doi.org/10.1021/acs.langmuir.7b03247.

FAO, 2011. Global Food Losses and Food Waste - Extent, Causes and Prevention (Rome).

Farouk, M.M., Mustafa, N.M., Wu, G., Krsinic, G., 2012. The "sponge effect" hypothesis: an alternative explanation of the improvement in the waterholding capacity of meat with ageing. Meat Sci. 90, 670-677. https://doi.org/10.1016/j. meatsci.2011.10.012.

Gaikwad, K.K., Singh, S., Ajji, A., 2019. Moisture absorbers for food packaging applications. Environ. Chem. Lett. 17, 609-628. https://doi.org/10.1007/s10311. 018-0810-z.

Geueke, B., Groh, K., Muncke, J., 2018. Food packaging in the circular economy: overview of chemical safety aspects for commonly used materials. J. Clean. Prod. 193, 491-505. https://doi.org/10.1016/j.jclepro.2018.05.005.

Glière, A., Delattre, C., 2006. Modeling and fabrication of capillary stop valves for planar microfluidic systems. Sens. Actuat. Phys. 130-131, 601-608. https://doi.org/ 10.1016/j.sna.2005.12.011.

Gouvêa, D.M., Mendonça, R.C.S., Lopez, M.E.S., Batalha, L.S., 2016. Absorbent food pads containing bacteriophages for potential antimicrobial use in refrigerated food 
products. LWT - Food Sci. Technol. (Lebensmittel-Wissenschaft -Technol.) 67, 159-166. https://doi.org/10.1016/j.lwt.2015.11.043.

Guo, Z., Zhang, J., Zhang, T., Li, C., Zhang, Y., Bai, J., 2012. Liquid viscosities, excess properties, and viscous flow thermodynamics of triethylene glycol + water mixtures at $\mathrm{T}=(298.15,303.15,308.15,313.15$, and 318.15) K. J. Mol. Liq. 165, 27-31. https://doi.org/10.1016/j.molliq.2011.10.003.

Gutierrez, M.M., Meleddu, M., Piga, A., 2017. Food losses, shelf life extension and environmental impact of a packaged cheesecake: a life cycle assessment. Food Res. Int. 91, 124-132. https://doi.org/10.1016/j.foodres.2016.11.031.

Hertog-Meischke, M.J.A. den, Smulders, F.J.M., van Logtestijn, J.G., 1998. The effect of storage temperature on drip loss from fresh beef. J. Sci. Food Agric. 78, 522-526. https://doi.org/10.1002/(SICI)1097-0010, 199812)78:4<522::AID-JSFA150>3.0 $\mathrm{CO} ; 2-\mathrm{F}$.

Huff-Lonergan, E., Lonergan, S.M., 2005. Mechanisms of water-holding capacity of meat: the role of postmortem biochemical and structural changes. Meat Sci. 71, 194-204. https://doi.org/10.1016/j.meatsci.2005.04.022.

Kakadellis, S., Woods, J., Harris, Z.M., 2021. Friend or foe: stakeholder attitudes towards biodegradable plastic packaging in food waste anaerobic digestion. Resour. Conserv. Recycl. 169, 105529. https://doi.org/10.1016/j.resconrec.2021.105529.

Kim, G.D., Jung, E.Y., Lim, H.J., Yang, H.S., Joo, S.T., Jeong, J.Y., 2013. Influence of meat exudates on the quality characteristics of fresh and freeze-thawed pork. Meat Sci. 95, 323-329. https://doi.org/10.1016/j.meatsci.2013.05.007.

Klimovič, M., Pekař, M., 2007. Untypical rheological behaviour of the lignitecarboxymethylcellulose-water dispersion system. Colloid Polym. Sci. 285, 865-872. https://doi.org/10.1007/s00396-006-1632-2.

Kumar, A., Ray, S., Das, G., 2018. Draining phenomenon in closed narrow tubes pierced at the top: an experimental and theoretical analysis. Sci. Rep. 8, 14114. https://doi. org/10.1038/s41598-018-32359-5.

Lanzani, F., Mauri, R., 1998. Sheet of Expanded Plastics Material with Absorbent Properties towards Aqueous Liquids. US5833894A.

LaRue, J.M., Cappel, C.E., Petlak, F.A., 2011. Container Having Internal Reservoir. US7921992B.

Lee, K.T., 2010. Quality and safety aspects of meat products as affected by various physical manipulations of packaging materials. Meat Sci. 86, 138-150. https://doi. org/10.1016/j.meatsci.2010.04.035.

Leite, W.O., Campos Rubio, J.C., Mata, F., Hanafi, I., Carrasco, A., 2018. Dimensional and geometrical errors in vacuum thermoforming products: an approach to modeling and optimization by multiple response optimization. Meas. Sci. Rev. 18, 113-122. https://doi.org/10.1515/msr-2018-0017.

Leu, T.S., Chang, P.Y., 2004. Pressure barrier of capillary stop valves in micro sample separators. Sens. Actuat. Phys. 115, 508-515. https://doi.org/10.1016/j. sna.2004.02.036.

Licciardello, F., 2017. Packaging, blessing in disguise. Review on its diverse contribution to food sustainability. Trends Food Sci. Technol. 65, 32-39. https://doi.org/ 10.1016/j.tifs.2017.05.003.

Maga, D., Hiebel, M., Aryan, V., 2019. A comparative life cycle assessment of meat trays made of various packaging materials. Sustain. Times 11. https://doi.org/10.3390/ su11195324.

McCool, R., Martin, P.J., 2011. Thermoforming process simulation for the manufacture of deep-draw plastic food packaging. Proc. Inst. Mech. Eng. Part E J. Process Mech. Eng. 225, 269-279. https://doi.org/10.1177/0954408911416292.

Miehle, E., Bader-Mittermaier, S., Schweiggert-Weisz, U., Hauner, H., Eisner, P., 2021 Effect of physicochemical properties of carboxymethyl cellulose on diffusion of glucose. Nutrients 13. https://doi.org/10.3390/nu13051398.

Morye, S.S., 2005. A comparison of the thermoformability of a PPE/PP blend with thermoformable ABS. Part I: small deformation methods. Polym. Eng. Sci. 45, 1369-1376. https://doi.org/10.1002/pen.20416.

Nisticò, R., 2020. Polyethylene terephthalate (PET) in the packaging industry. Polym. Test. 90 https://doi.org/10.1016/j.polymertesting.2020.106707.

Otoni, C.G., Espitia, P.J.P., Avena-Bustillos, R.J., McHugh, T.H., 2016. Trends in antimicrobial food packaging systems: emitting sachets and absorbent pads. Food Res. Int. 83, 60-73. https://doi.org/10.1016/j.foodres.2016.02.018.
Patnaik, A., Rengasamy, R.S., Kothari, V.K., Ghosh, A., 2006. Wetting and wicking in fibrous materials. Textil. Prog. 38, 1-105. https://doi.org/10.1533/ jotp.2006.38.1.1.

Ralston, J., Popescu, M., Sedev, R., 2008. Dynamics of wetting from an experimental point of view. Annu. Rev. Mater. Res. 38, 23-43. https://doi.org/10.1146/annurev. matsci.38.060407.130231.

Realini, C.E., Marcos, B., 2014. Active and intelligent packaging systems for a modern society. Meat Sci. 98, 404-419. https://doi.org/10.1016/j.meatsci.2014.06.031.

Ren, T., Qiao, M., Huang, T.S., Weese, J., Ren, X., 2018. Efficacy of N-halamine compound on reduction of microorganisms in absorbent food pads of raw beef. Food Control 84, 255-262. https://doi.org/10.1016/j.foodcont.2017.08.006.

Saedi, S., Shokri, M., Kim, J.T., Shin, G.H., 2021. Semi-transparent regenerated cellulose/ZnONP nanocomposite film as a potential antimicrobial food packaging material. J. Food Eng. 307, 110665. https://doi.org/10.1016/j. jfoodeng.2021.110665.

Sahin, S., Sumnu, S.G., 2007. Size, shape, volume, and related physical attributes. In: Physical Properties of Foods. Springer, New York, pp. 1-37. https://doi.org/ 10.1007/0-387-30808-3_1.

Schumann, B., Schmid, M., 2018. Packaging concepts for fresh and processed meat recent progresses. Innovat. Food Sci. Emerg. Technol. 47, 88-100. https://doi.org/ 10.1016/j.ifset.2018.02.005.

Si, Y., Yu, C., Dong, Z., Jiang, L., 2018. Wetting and spreading: fundamental theories to cutting-edge applications. Curr. Opin. Colloid Interface Sci. 36, 10-19. https://doi. org/10.1016/j.cocis.2017.12.006.

Thio, T.H.G., Soroori, S., Ibrahim, F., Al-Faqheri, W., Soin, N., Kulinsky, L., Madou, M., 2013. Theoretical development and critical analysis of burst frequency equations for passive valves on centrifugal microfluidic platforms. Med. Biol. Eng. Comput. 51, 525-535. https://doi.org/10.1007/s11517-012-1020-7.

Throne, J., 2017. Thermoforming. In: Applied Plastics Engineering Handbook: Processing, Materials, and Applications, second ed. Elsevier Inc., pp. 345-375. https://doi.org/10.1016/B978-0-323-39040-8.00016-X

Ursu, A.V., Marcati, A., Michaud, P., Djelveh, G., 2016. Valorisation of industrial cooked ham by-products as functional ingredients. J. Food Eng. 190, 54-60. https://doi.org/ 10.1016/j.jfoodeng.2016.06.013.

Vesel, A., Junkar, I., Cvelbar, U., Kovac, J., Mozetic, M., 2008. Surface modification of polyester by oxygen- and nitrogen-plasma treatment. Surf. Interface Anal. 40, 1444-1453. https://doi.org/10.1002/sia.2923.

Walker, T.R., McGuinty, E., Charlebois, S., Music, J., 2021. Single-use plastic packaging in the Canadian food industry: consumer behavior and perceptions. Humanit. Soc. Sci. Commun. 8 https://doi.org/10.1057/s41599-021-00747-4.

Wang, Z., Yen, H.Y., Chang, C.C., Sheng, Y.J., Tsao, H.K., 2013. Trapped liquid drop at the end of capillary. Langmuir 29, 12154-12161. https://doi.org/10.1021/ la4026602.

Wardhani, R., Putu, S., Sanjoto, B.L., Nur, H., Hari, S., 2014. Numerical simulation of multipoint forming with circular die pins in hexagonal packing. Appl. Mech. Mater. 493, 589-593. https://dx.doi.org/10.4028/www.scientific.net/AMM.493.589.

Wheeler, M., 2019. Why send 750 million soiled absorbent pads to landfill if there is a better way? Food \& Beverage Industry News [WWW Document]. URL accessed 9.15.21. https://www.foodmag.com.au/why-send-750-million-soiled-absorbentpads-to-landfill-if-there-is-a-better-way/.

Yang, L., Chen, J., Guo, Y., Zhang, Z., 2009. Surface modification of a biomedical polyethylene terephthalate (PET) by air plasma. Appl. Surf. Sci. 255, 4446-4451. https://doi.org/10.1016/j.apsusc.2008.11.048.

Zhao, T., Jiang, L., 2018. Contact angle measurement of natural materials. Colloids Surf. B Biointerfaces 161, 324-330. https://doi.org/10.1016/j.colsurfb.2017.10.056.

Zhao, X., Cornish, K., Vodovotz, Y., 2020. Narrowing the gap for bioplastic use in food packaging: an update. Environ. Sci. Technol. 54, 4712-4732. https://doi.org/ 10.1021/acs.est.9b03755.

Zimmermann, M., Hunziker, P., Delamarche, E., 2008. Valves for autonomous capillary systems. Microfluid. Nanofluidics 5, 395-402. https://doi.org/10.1007/s10404-0070256-2. 